\title{
Prediction of Life-Threatening Arrhythmias - Still an Unresolved Problem
}

\author{
Kristina Hermann Haugaa ${ }^{a-c}$ Thor Edvardsen ${ }^{a-c}$ Jan P. Amlie ${ }^{a, c}$ \\ a Department of Cardiology and ${ }^{\mathrm{b}}$ Institute for Surgical Research, Oslo University Hospital, Rikshospitalet, and \\ 'University of Oslo, Oslo, Norway
}

\section{Key Words}

Ventricular arrhythmias $\cdot$ Risk stratification $\cdot$ Strain

echocardiography $\cdot$ Ventricular function

\begin{abstract}
A major challenge in current cardiology is to predict who will die suddenly from ventricular arrhythmias. Ventricular arrhythmias are the most common cause of sudden cardiac death, occurring in about 1-2:1,000 inhabitants yearly, and is most frequently due to coronary artery disease. Patients with increased risk of ventricular arrhythmias can be offered medical treatment and ultimately an implantable cardioverter defibrillator (ICD). Left ventricular ejection fraction $(\mathrm{EF})$ is currently the main risk stratification tool used to select patients for ICD therapy. However, EF is insufficient in predicting arrhythmic risk. A number of techniques have been presented to improve arrhythmic risk stratification without having reached clinical utility. Conduction abnormalities and dispersion of action potential duration forms the substrate for malignant ventricular arrhythmias in infarcted tissue as in several cardiomyopathies. The ability to assess electrical dispersion in patients noninvasively has been limited. Myocardial strain by echocardiography has been presented
\end{abstract}

as an accurate tool for assessing myocardial function and timing. Inhomogeneous and dispersed myocardial contraction has been related to the occurrence of ventricular arrhythmias and seems to be a promising tool in risk stratification. This review focuses on arrhythmia mechanisms and novel echocardiographic tools for assessing risk of ventricular arrhythmias.

Copyright $\odot 2011$ S. Karger AG, Basel

\section{Introduction}

Ventricular arrhythmia remains the most common cause of sudden cardiac death in Western societies occurring in 1-2:1,000 inhabitants per year [1]. A major challenge in current cardiology that is still an unresolved problem is to predict who will die suddenly from ventricular arrhy thmias. The most frequent cause of ventricular arrhythmias and sudden cardiac death in individuals over the age of 30 is coronary artery disease, while inherited cardiac disease is the most frequent cause in individuals below 30 years of age [1]. Unfortunately, in the majority of patients dying suddenly, death is the first symptom of the heart disease [2]. Risk stratification and

Jan P. Amlie

Department of Cardiology, Oslo University Hospital, Rikshospitalet

Sognsvannsveien 27

NO-0027 Oslo (Norway)

Tel. +47 2307 0000, E-Mail jamlie@ ous-hf.no 


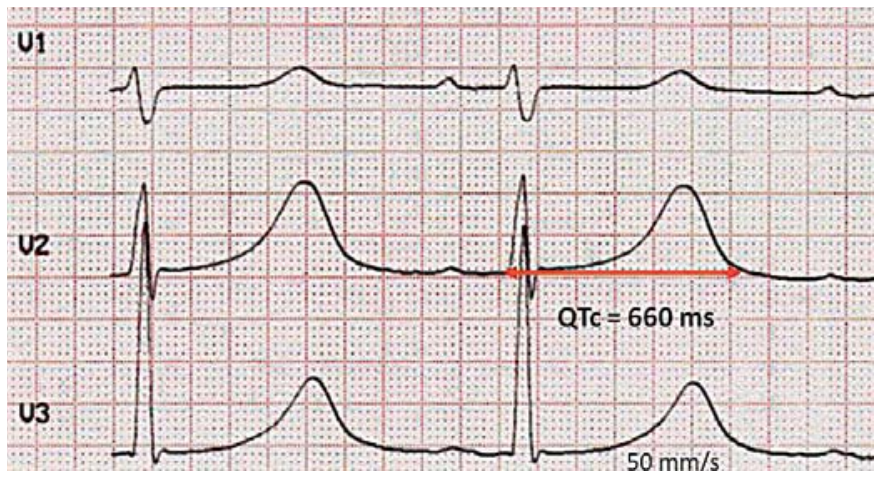

Fig. 1. ECG with markedly prolonged QT interval of $660 \mathrm{~ms}$.

prevention of sudden death may therefore be of value in certain selected groups of individuals, but there is currently lack of powerful tools for screening of the general population where the majority of sudden cardiac deaths occur.

When a patient has been identified to have increased risk of ventricular arrhythmias, treatment can be offered both in terms of medication and ultimately with an implantable cardioverter defibrillator (ICD). Several studies have demonstrated that ICD therapy reduces mortality from ventricular arrhythmias in patients with ischemic heart disease [3-6]. The occurrence of ventricular tachycardia (VT) is a strong predictor of further arrhythmic events [7].

In patients who have survived a malignant ventricular arrhythmia, ICD implantation for secondary prevention is well established. The major challenge is to select patients for ICD primary prevention therapy, that is, to predict who is at risk of dying suddenly among patients in whom arrhythmic events have not yet occurred.

This review will include risk stratification in patients with increased risk of ventricular arrhythmias and sudden cardiac death with inherited cardiac diseases and patients with coronary artery disease.

\section{Long QT Syndrome}

The long QT syndrome (LQTS) is an inherited cardiac arrhythmic disease predisposing to life-threatening ventricular arrhythmias and sudden cardiac death. LQTS is characterized by prolongation of the QT interval on ECG (fig. 1).

LQTS has served as a model of understanding the genesis of ventricular arrhythmias during the past decades.
LQTS is caused by mutations in genes encoding for cardiac ion channels which are leading to prolonged action potential duration and dispersion of action potential repolarization. Both prolonged action potential duration with development of early afterdepolarization and dispersion of electrical repolarization are considered to be important mechanisms causing ventricular arrhythmias in these patients [8] (fig. 2).

Risk stratification of ventricular arrhythmias in LQTS patients is currently based on history of syncope-, genotype-, gender- and heart rate-corrected QT interval (QTc) on ECG [9]. QTc is the most important current tool to screen patients with unexplained syncopes and to predict who is at risk of dying suddenly in known LQTS mutation carriers. However, substantial overlap in QTc values between LQTS patients with and without arrhythmic events make risk stratification challenging.

Genetic testing has become more available in the last years, resulting in a large amount of known individuals carrying an LQTS-related mutation. The penetrance of the disease is variable and a substantial proportion of mutation carriers will remain asymptomatic during lifetime. The overall risk that adult mutation carriers with no symptoms of LQTS will experience arrhythmias during their later lifetime is low and QTc has failed to be a significant predictor of outcome in these individuals [10]. Prophylactic treatment involves lifelong $\beta$-blocker therapy and requires adequate compliance. Decisions regarding preventive treatment are often difficult.

Genotyping has achieved clinical usefulness in risk stratification. LQT1 patients (KCNQ1 mutations) have excellent protection of $\beta$-blocker medication, while protection is not $100 \%$ in LQT2 (HERG mutations) and insufficient in LQT3 patients (SCN5A mutations) [9]. LQT2 patients are particularly exposed to arrhythmic risk by QT-prolonging drugs. Double mutation carriers, patients with Jervell and Lange-Nielsen syndrome, have the most severe phenotype and concomitant deafness [11]. ICD therapy is indicated in LQTS patients with aborted cardiac arrest or arrhythmic events despite $\beta$-blocker medication. Although ICD is a life-saving therapy in these patients, there are also several negative aspects associated with this therapy especially in young patients. Inappropriate shocks due to prominent $\mathrm{T}$ waves is one example of specific complications that can occur in these patients in addition to the complications associated with young age at ICD implantation with a number of lead and battery replacements during life-long therapy [12].

Left ventricular (LV) function has been considered to be normal in LQTS patients and echocardiography in 
Fig. 2. Mechanisms of arrhythmias in LQTS. Potassium channels (IKr and IKs, circled) are the most frequently affected ion channels in LQTS. Defect ion channels lead to a prolongation of action potential duration (mid left figure). Action potential prolongation is inhomogeneously distributed throughout the ventricles leading to dispersion of electrical repolarization (mid right figure).

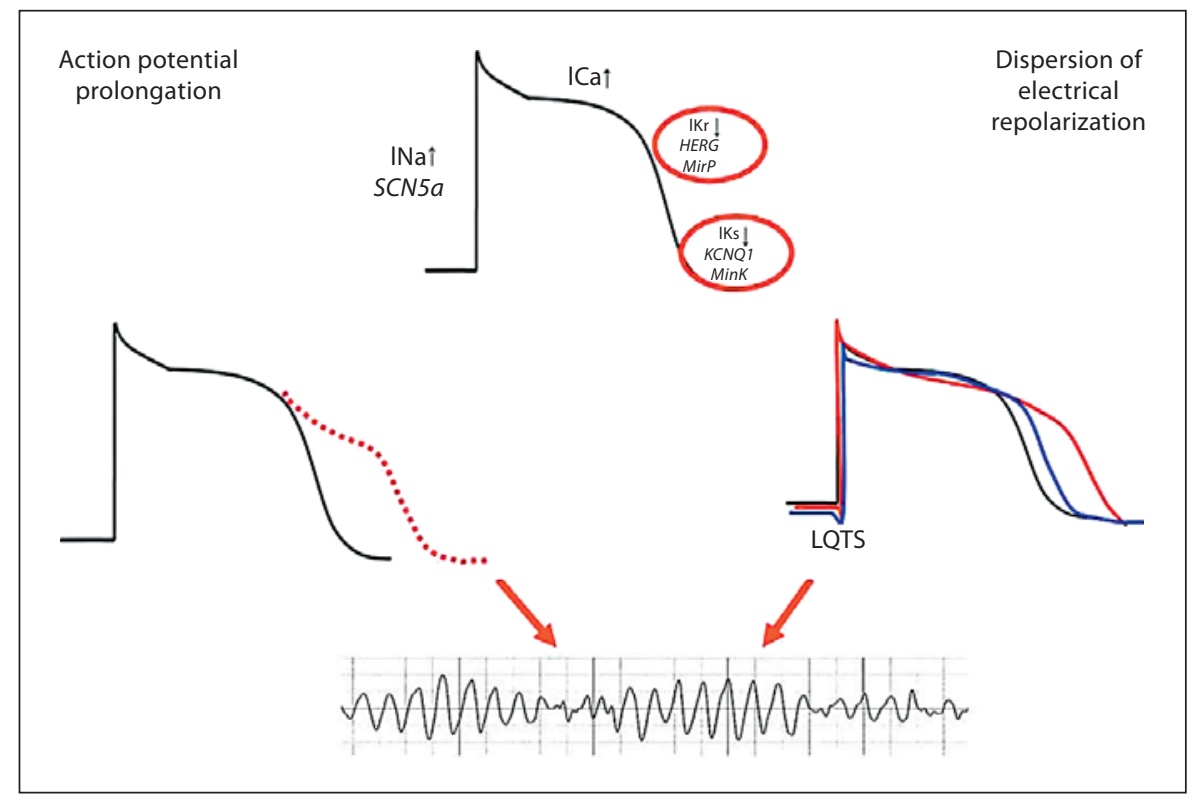

these patients has traditionally been performed only to exclude additional or to differentiate from other heart diseases. There is, however, support for the assumption that prolonged action potential duration and electrical dispersion may cause wall motion abnormalities in these patients which can be assessed by echocardiography $[13$, 14] (fig. 3).

\section{New Echocardiographic Modalities}

Modern echocardiographic techniques have been developed during the last decades including tissue Doppler imaging and strain echocardiography (STE) [15]. The advantages of these techniques are better regional assessment of myocardial function and timing. Minor degrees of myocardial contraction heterogeneity and subtle contraction dyssynchrony can be demonstrated by these techniques [16]. STE is based on conventional grey scale echocardiographic images and provides segmental analyses of $16 \mathrm{LV}$ segments. Measurements can be done simultaneously from multiple regions of interest. STE has been showed to be a very accurate method for assessment of LV function and is a validated technique [17]. Visual assessment of regional myocardial function from twodimensional image is the standard echocardiographic method to assess ventricular function and has had that position since the introduction of two-dimensional echocardiography. The method has also been established as a clinically important tool in detecting regional ventricular function, but has limited ability to detect more subtle

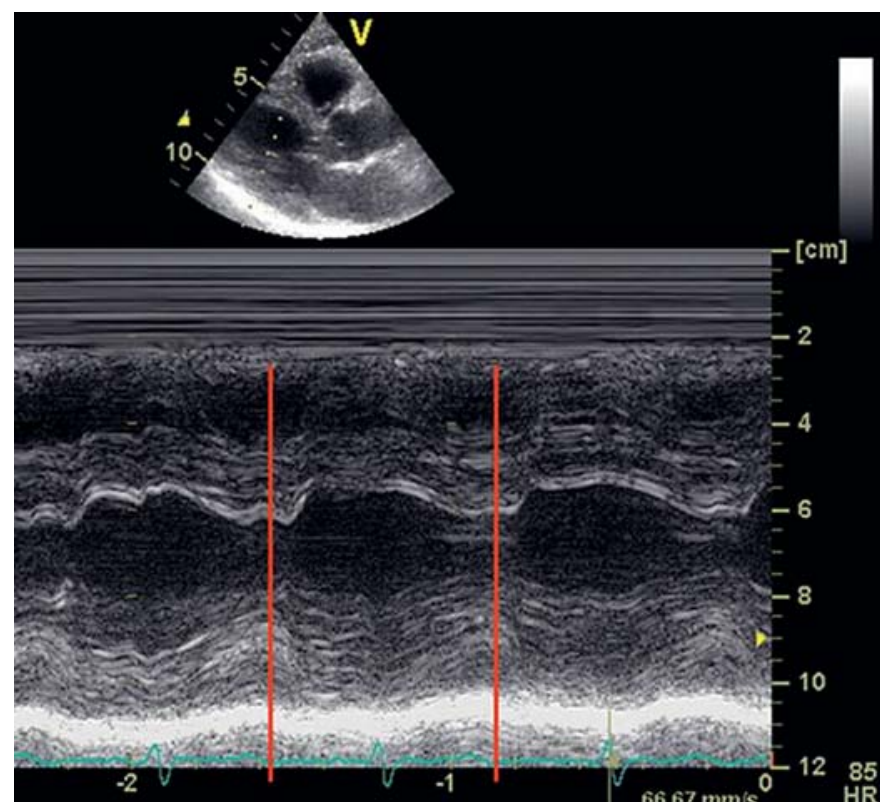

Fig. 3. M-mode recording from an LQTS patient. Red lines indicate the end of the T wave from the ECG below. Contraction duration in the interventricular septum is prolonged and exceeds the time of the end of the T wave.

changes in function and changes in timing of myocardial motion throughout systole and diastole. Visual assessment of myocardial function has therefore been unsuccessful to detect regional wall motion abnormalities in LQTS patients. 
Fig. 4. Strain curves from a healthy individual (left panel) and from an LQTS patient (right panel). Contraction duration is prolonged in the LQTS patient compared to the healthy individual. Modified from Haugaa et al. [18].
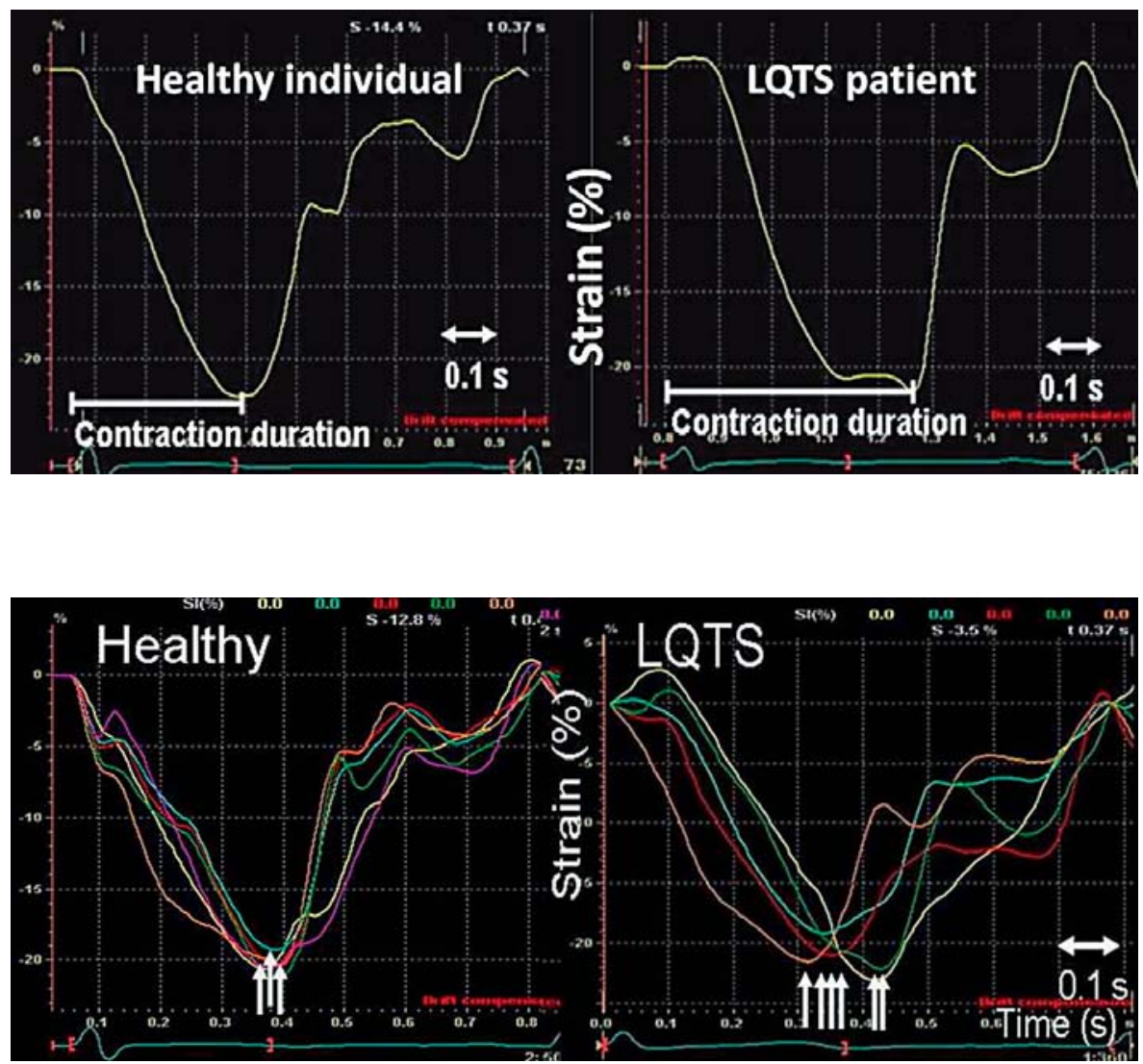

Fig. 5. Myocardial strain curves from 6 different locations in a healthy individual (left panel) and a LQTS patient (right panel). White arrows indicate timing of maximum myocardial shortening. The LQTS patient shows pronounced dispersion in timing of contraction defined as mechanical dispersion compared to the healthy individual.

\section{Studies in LQTS Patients}

Accurate assessment of myocardial function by myocardial velocities and strain has revealed that LQTS patients have prolonged myocardial contraction $[18,19]$ (fig. 4). This may be due to the prolonged action potential duration in these patients and is in accordance with experimental studies showing that a prolongation of the action potential duration is associated with a prolonged contraction [20].

Furthermore, strain studies showed that prolonged contraction duration was inhomogeneously distributed throughout the ventricles in LQTS patients leading to a dispersion of contraction duration defined as mechanical dispersion (fig. 5). Importantly, in these studies, prolonged and dispersed myocardial contraction was associated with a higher risk of cardiac arrhythmias in LQTS patients. Mechanical dispersion by myocardial strain showed better sensitivity and specificity in predicting arrhythmic events compared to QTc [19]. Optimal cutoff value for mechanical dispersion was $\geq 33 \mathrm{~ms}$ and identified LQTS mutation carriers with a history of events with a sensitivity of $76 \%$ and a specificity of $91 \%$. QTc $\geq 460$ ms showed a sensitivity of $42 \%$ and a specificity of $81 \%$ to identify mutation carriers with a history of events.

The echocardiographic technique may be proposed as an additional risk stratification tool in LQTS patients. Specifically, the method may be of help in decisions about preventive $\beta$-blocker therapy in adult asymptomatic mutation carriers.

The specific patterns of myocardial contraction abnormalities reported may depend on the concomitant electrical disorder in these patients and may represent the mechanical consequence of electric arrhythmogenic factors. LQTS may no longer be regarded as a purely electrical disease [21].

\section{Brugada Syndrome}

The Brugada syndrome (BrS) has an estimated prevalence of $1: 10,000$ and is associated with high mortality [22]. Mutations in genes encoding for the cardiac sodium channel are found in $20-30 \%$ of patients with BrS. Typical ECG changes with ST elevation in right precordial 
leads ( $\geq 2 \mathrm{~mm}$ concave ST segment elevation in ECG lead V1 and V2) are hallmarks of the disease and can be present spontaneously or appear after pharmacological challenge with sodium channel blockers such as flecainid. Risk prediction of ventricular arrhythmias in patients and relatives of patients with $\mathrm{BrS}$ is difficult. Spontaneous ECG changes are markers of increased risk. Holter monitoring may be used to detect transient ECG changes. The role of electrophysiological study in risk stratification was initially reported to be significant, but has been debated and regarded as not predictive of ventricular arrhythmias in a recent study of $>1,000$ patients with $\mathrm{BrS}$ [23].

\section{Patients after Myocardial Infarction}

Patients after myocardial infarction (MI) are at high risk for cardiac arrhythmic events and sudden cardiac death [1]. The immediate and 30-day mortality after MI has decreased markedly over the last $10-15$ years. The decreased mortality is mainly due to proper treatment with percutaneous coronary intervention and thrombolysis, but is also due to improved medical therapy as $\beta$-blockade and ACE/inhibitors. Currently, LV ejection fraction (EF) is the primary parameter used to select patients for ICD therapy after MI. Impaired EF is shown to be a marker of increased cardiovascular mortality and sudden cardiac death. Earlier echocardiographic studies have observed that an EF of $40 \%$ serves as the threshold for identifying high-risk individuals [24]. However, EF has reduced sensitivity in predicting sudden death; less than $50 \%$ of patients with prior MI who die suddenly have EF below 30\% [25]. A number of other diagnostic tests have been proposed to improve the accuracy for selection of patients for ICD therapy. Currently available data, however, are not sufficient to routinely recommend additional risk-stratification methods for selection of patients for ICD therapy [6].

\section{Pathophysiological Mechanisms of Arrhythmias and Possible Methods to Detect and Predict Them}

An unresolved question is what factors cause a patient after MI, who may remain stable for months after the infarction, to suddenly become electrically unstable and develop malignant arrhythmias. To predict which patients are most likely to develop life-threatening ventricular arrhythmias, one first needs to understand the patho- physiological mechanisms behind them. There is general agreement that ventricular arrhythmias need a substrate and a trigger to occur.

\section{Substrates of Arrhythmias after MI}

The presence of myocardial scar forms the substrate for malignant arrhythmias [26]. Heterogeneity in scar tissue creates areas of slow conduction that generate dispersion of cardiac action potentials and provide the substrate for ventricular arrhythmias [27]. The normal beating human heart has a certain dispersion of repolarization. Action potentials in the endocardium last longer than in the epicardium due to different ionic movements. Gradients of long to short action potential durations from the apex to the base have also been demonstrated. The overall electrical activity is reflected in a normal QRS complex and a normal $\mathrm{T}$ wave. In infarcted tissue, however, pronounced electrical dispersion, including both activation time and refractoriness, is a known arrhythmogenic substrate [28-30].

Inhomogeneous start of action potentials in infarcted tissue due to areas of slowed conduction is the background behind the predictive value of signal averaging electrocardiogram (SAECG) in post-MI patients. The SAECG compares and averages around 300 consecutive QRS complexes to produce a filtered QRS complex that provides information on the presence of ventricular late potentials. Presence of late potential is an indicator of slowed conduction and has been documented in $25-50 \%$ of patients after MI [31]. Late potentials showed to be a good predictor for malignant arrhythmias in patients with low EF in the MUSTT study [7]. With the increasing use of primary percutaneous coronary intervention in the treatment of AMI, the prognostic value of the SAECG has become less clear. The usefulness of SAECG in risk assessment of ventricular arrhythmias is limited by a low positive predictive value but may be used to identify lowrisk patients due to a relatively high negative predictive value of about $90 \%$.

Inhomogeneous start of action potentials in infarcted tissue will lead to an inhomogeneous end of repolarization. The measurement of QT dispersion on ECG as an indicator of dispersion of ventricular repolarization was presented as a promising tool in risk stratification of arrhythmias two decades ago [32]. However, the method has not achieved the clinical value as initially expected due to challenges in T-wave definition and poor reproducibility [33]. Electrical alternans of the T-wave (that is, alternating amplitude from beat to beat) on the ECG is thought to be due to dispersion of repolarization and has 


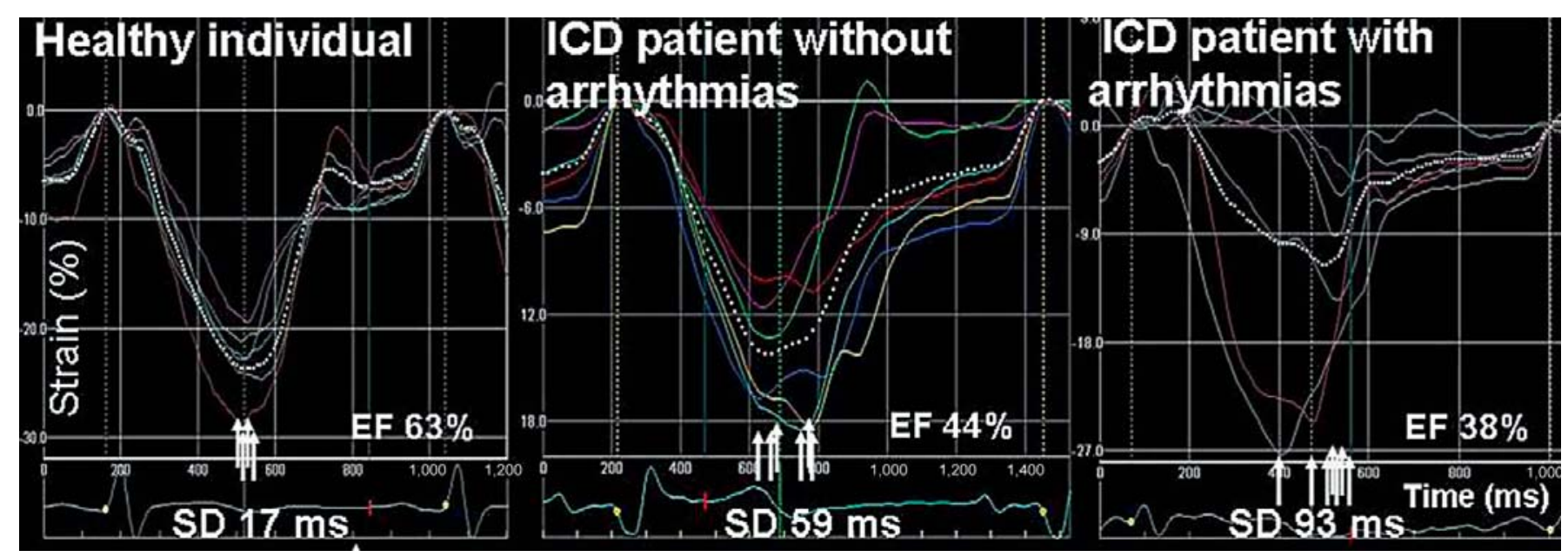

Fig. 6. Homogenous timing of myocardial contraction by STE in a healthy individual as well as mechanical dispersion in an ICD patient with and without arrhythmias during follow-up. The ICD patient with recurrent arrhythmias showed most pronounced mechanical dispersion indicated by white arrows. Modified from Haugaa et al. [41].

been demonstrated to be associated with life-threatening ventricular arrhythmias after MI [34]. Due to a low positive predictive value, and similar to SAECG, the value of T-wave alternans in risk stratification may actually be in deciding which patients are least likely to benefit from ICD therapy.

Electrophysiological testing in patients with previous AMI is an invasive method to investigate if the scarred myocardium is able to sustain re-entrant ventricular arrhythmias. Electrophysiological testing is recommended in some of the current guidelines for selection of post-MI patients for prophylactic ICD therapy who have symptoms suggestive of VT [1]. Drawbacks are the invasive nature and the wide range of reported sensitivity of the method. The future role of this test may lie in its combined use with other and noninvasive tests to refine the selection of potential ICD recipients.

It has been shown that a sub-threshold stimulus on the body surface can modulate the QRS complex so that slow conduction in some areas can be detected. The so-called Wedensky index may be a predictor for malignant ventricular arrhythmias after MI. The Wedensky index indicates a high negative predictive value regarding the occurrence of VT [35]. Prospective studies will show the value of this technique.

\section{Triggers of Arrhythmias after MI}

Ectopic activity from the border zone of the myocardial scar is an important trigger. This trigger can be en- hanced by sympathetic stimulation and detected by 24 hour Holter recording. It has been shown that the presence of nonsustained VT predicted sudden cardiac death in a modern post-MI population and may be useful in those with $\mathrm{EF}>35 \%$ [36]. Increased sympathetic activity favors the development of cardiac arrhythmias, whereas increased vagal tone appears to be protective [37]. Sympathetic and parasympathetic activity can be detected indirectly by heart rate variability analysis and heart rate turbulence, but none of these methods have come into general clinical practice due to low sensitivity and specificity.

Triggers like ectopic activity can be enhanced by low potassium concentration, eventually together with low calcium concentration, and prolongation of the sodium current.

\section{Imaging Techniques for Risk Stratification of Arrhythmias beyond EF}

The extent of scar tissue has been correlated with the risk of arrhythmias in patients after MI. MRI studies have demonstrated that quantification of the peri-infarct zone by contrast-enhanced cardiovascular MRI was an independent predictor of mortality following AMI [38] and that tissue heterogeneity in the peri-infarct zone was likely to provide the proarrhythmic substrate [39]. This approach is interesting and needs to be further investigated. 


\section{STE in Patients after MI}

Strain measurements by echocardiography has recently been demonstrated to be a more accurate tool for quantification of myocardial function after MI compared to EF using MRI studies as a gold standard [40]. Furthermore, reduced LV function by global strain has been shown to predict appropriate ICD therapy in a population of 85 post-MI patients with ICD, while EF did not [41]. Assessment of cardiac function as a risk predictor of cardiac arrhythmias may be refined by STE, representing a more regional measure compared to EF.

The principles of mechanical dispersion as an arrhythmogenic factor were tested in post-MI patients. Post-MI patients with recurrent arrhythmic events showed a more dispersed myocardial contraction assessed by STE compared to post-MI patients without arrhythmic events (fig. 6) [41]. Mechanical dispersion was a strong predictor of malignant ventricular arrhythmias, independently of EF and predicted arrhythmias with a hazard ratio of 1.24 (95\% CI 1.07-1.43, p < 0.01). EF was no significant predictor of arrhythmias in multivariate analyses [41]. These findings supported the idea that tissue heterogeneity in and around scarred myocardium leads to a dispersed myocardial contraction and is associated with risk of arrhythmic events.

In post-MI patients, measurements of mechanical dispersion may add important information about risk of arrhythmia independently of EF. These findings support the idea that mechanical dispersion might be useful to identify risk of arrhythmias in post-MI patients with relatively preserved EF who do not fulfill current ICD indications. Future trials should investigate if dispersed contraction can be used to select additional patients for ICD therapy among the majority of post-MI patients with relatively preserved EF in whom current ICD indications fail.

\section{Arrhythmogenic Right Ventricular Cardiomyopathy}

Arrhythmogenic right ventricular cardiomyopathy (ARVC) is an inherited cardiomyopathy which accounts for a substantial proportion of sudden unexpected cardiac death in previously healthy young individuals [42]. Prevalence has been estimated to be at least 1 in 1,000 [42]. Recent molecular genetic reports have revealed ARVC as mainly a desmosomal disease. Penetrance is age and gender dependent and the phenotype is highly variable.

Mechanisms for arrhythmias in early stages of ARVC are probably due to dysfunction of desmosomal proteins and disturbed cell to cell coupling [43]. In later stages of ARVC when structural abnormalities in the myocardium have developed, re-entrant ventricular arrhythmias can occur due to the scar-related substrate. Therefore, electrical conduction disturbances with consequent electrical dispersion have been suggested as an important mechanism of ventricular arrhythmias $[44,45]$.

In ARVC, late potentials are frequently found indicating areas with slow conduction, mainly in the right ventricle. This can sometimes be seen in standard 12-lead ECG as an epsilon wave in V1. In addition, repolarization abnormalities can be visible on ECG as T wave inversion. In the most common right ventricular type of ARVC, a negative $\mathrm{T}$ wave is found from V1 to V3. However, risk stratification of affected patients is still incomplete. Neither family history nor genotype have been predictors of outcome. The available data suggest that young age, prior cardiac arrest, fast VT with different morphologies, syncopes, severe RV dysfunction and LV involvement are potential predictors of sudden death and worse outcome [46].

\section{STE in Patients with ARVC}

In all stages of ARVC, electrical conduction delay with consequent electrical dispersion has been suggested as a mechanism of ventricular arrhythmias $[44,45]$. The novel method of mechanical dispersion may therefore have a potential role as risk stratification tool in ARVC [47].

\section{Dispersion of Myocardial Contraction in Different Cardiac Conditions}

In this report, mechanical dispersion has been reviewed as a possible risk stratification tool in LQTS patients, in post-MI patients and in ARVC patients. The mechanisms for arrhythmias in LQTS, ARVC and in infarcted myocardial tissue are different, but have similarities regarding electrical dispersion. In LQTS patients, inherited ion channel defects result in prolonged APD. Inhomogeneous prolongation of APD in LQTS results in dispersed electrical repolarization, which is regarded as an important arrhythmia mechanism. In ARVC patients, mechanisms of arrhythmias are probably stage dependent, but electrical dispersion has been considered to be of importance in early and later stages of the disease [44, 45]. In post-MI patients delayed start of ventricular activation in scarred myocardium leads to a dispersed recovery of excitability [29], finally resulting in dispersed electrical repolarization. One might therefore speculate that 
electrical dispersion may be regarded as the final common pathway of arrhythmia mechanism in all three conditions.

The extent of mechanical dispersion is influenced by the concomitant contractile impairment in infarcted tissue and presence of fibrosis in ARVC which is not present in LQTS patients. Contractile impairment will pronounce mechanical dispersion. The ranges and values of mechanical dispersion which are related to increased arrhythmic risk will therefore not necessarily be interchangeable between different myocardial diseases.

Echocardiography is readily available and is therefore suitable as a widespread risk stratification tool. However, as other imaging techniques, observer dependency is significant for echocardiographic measurements. This is well known from variations in EF measurements. We believe that strain measurements are equally observer dependent. To overcome this problem, each laboratory has to gain experience in strain measurements. Strain measurements by speckle tracking technique have been successfully automated by commercially available software (Echopac; GE Vingmed). The time intervals needed for calculations of mechanical dispersion are automated and relatively easily available in this software.

In summary, prediction of malignant ventricular arrhythmias remains a major challenge. No single test has the accuracy needed to predict sudden death and the use of several parameters in combination seems to be the most promising way of future risk prediction. More sophisticated methods are needed to get better clinical tools for predicting malignant ventricular arrhythmias. Modern echocardiographic techniques contribute to an accurate assessment of myocardial function and timing and may be useful as additional risk stratification tools in patients at risk of ventricular arrhythmias.

\section{References}

1 Zipes DP, Camm AJ, Borggrefe M, Buxton AE, Chaitman B, Fromer M, Gregoratos G, Klein G, Moss AJ, Myerburg RJ, Priori SG, Quinones MA, Roden DM, Silka MJ, Tracy C, Smith SC Jr, Jacobs AK, Adams CD, Antman EM, Anderson JL, Hunt SA, Halperin JL, Nishimura R, Ornato JP, Page RL, Riegel B, Priori SG, Blanc JJ, Budaj A, Camm AJ, Dean V, Deckers JW, Despres C, Dickstein K, Lekakis J, McGregor K, Metra M, Morais J, Osterspey A, Tamargo JL, Zamorano JL: ACC/AHA/ESC 2006 guidelines for management of patients with ventricular arrhythmias and the prevention of sudden cardiac death: a report of the American College of Cardiology/American Heart Association Task Force and the European Society of Cardiology Committee for Practice Guidelines (Writing Committee to Develop Guidelines for Management of Patients With Ventricular Arrhythmias and the Prevention of Sudden Cardiac Death). J Am Coll Cardiol 2006; 48:e247-e346.

-2 Myerburg RJ, Kessler KM, Castellanos A: Sudden cardiac death. Structure, function, and time-dependence of risk. Circulation 1992;85:I2-10.

-3 Moss AJ, Hall WJ, Cannom DS, Daubert JP, Higgins SL, Klein H, Levine JH, Saksena S, Waldo AL, Wilber D, Brown MW, Heo M: Improved survival with an implanted defibrillator in patients with coronary disease at high risk for ventricular arrhythmia. Multicenter Automatic Defibrillator Implantation Trial Investigators. N Engl J Med 1996;335: 1933-1940.
-4 Moss AJ, Zareba W, Hall WJ, Klein H, Wilber DJ, Cannom DS, Daubert JP, Higgins SL, Brown MW, Andrews ML: Prophylactic implantation of a defibrillator in patients with myocardial infarction and reduced ejection fraction. N Engl J Med 2002;346:877-883.

$\checkmark 5$ Buxton AE, Ellison KE, Lorvidhaya P, Ziv O: Left ventricular ejection fraction for sudden death risk stratification and guiding implantable cardioverter-defibrillators implantation. J Cardiovasc Pharmacol 2010;55: 450-455.

6 Passman R, Kadish A: Sudden death prevention with implantable devices. Circulation 2007;116:561-571

7 Buxton AE, Lee KL, Fisher JD, Josephson ME, Prystowsky EN, Hafley G: A randomized study of the prevention of sudden death in patients with coronary artery disease. Multicenter Unsustained Tachycardia Trial Investigators. N Engl J Med 1999;341:18821890.

$>8$ el-Sherif N, Zeiler RH, Craelius W, Gough WB, Henkin R: QTU prolongation and polymorphic ventricular tachyarrhythmias due to bradycardia-dependent early afterdepolarizations. Afterdepolarizations and ventricular arrhythmias. Circ Res 1988;63:286305.

-9 Priori SG, Schwartz PJ, Napolitano C, Bloise R, Ronchetti E, Grillo M, Vicentini A, Spazzolini C, Nastoli J, Bottelli G, Folli R, Cappelletti D: Risk stratification in the long-QT syndrome. N Engl J Med 2003;348:18661874 .
10 Goldenberg I, Moss AJ, Bradley J, Polonsky S, Peterson DR, McNitt S, Zareba W, Andrews ML, Robinson JL, Ackerman MJ, Benhorin J, Kaufman ES, Locati EH, Napolitano C, Priori SG, Qi M, Schwartz PJ, Towbin JA, Vincent GM, Zhang L: Long-QT syndrome after age 40. Circulation 2008;117:2192-2201.

-11 Schwartz PJ, Spazzolini C, Crotti L, Bathen J, Amlie JP, Timothy K, Shkolnikova M, Berul CI, Bitner-Glindzicz M, Toivonen L, Horie M, Schulze-Bahr E, Denjoy I: The Jervell and Lange-Nielsen syndrome: natural history, molecular basis, and clinical outcome. Circulation 2006;113:783-790.

12 Schwartz PJ, Spazzolini C, Priori SG, Crotti L, Vicentini A, Landolina M, Gasparini M, Wilde AA, Knops RE, Denjoy I, Toivonen L, Monnig G, Al-Fayyadh M, Jordaens L, Borggrefe M, Holmgren C, Brugada P, De RL, Hohnloser SH, Brink PA: Who are the longQT syndrome patients who receive an implantable cardioverter-defibrillator and what happens to them?: data from the European Long-QT Syndrome Implantable Cardioverter-Defibrillator (LQTS ICD) Registry. Circulation 2010;122:1272-1282.

13 Nador F, Beria G, De Ferrari GM, StrambaBadiale M, Locati EH, Lotto A, Schwartz PJ: Unsuspected echocardiographic abnormality in the long QT syndrome. Diagnostic, prognostic, and pathogenetic implications. Circulation 1991;84:1530-1542.

14 De Ferrari GM, Nador F, Beria G, Sala S, Lotto A, Schwartz PJ: Effect of calcium channel block on the wall motion abnormality of the idiopathic long QT syndrome. Circulation 1994;89:2126-2132. 
- 15 Edvardsen T, Urheim S, Skulstad H, Steine K, Ihlen H, Smiseth OA: Quantification of left ventricular systolic function by tissue Doppler echocardiography: added value of measuring pre-and postejection velocities in ischemic myocardium. Circulation 2002; 105:2071-2077.

- 16 Yu CM, Sanderson JE, Marwick TH, Oh JK: Tissue Doppler imaging a new prognosticator for cardiovascular diseases. J Am Coll Cardiol 2007;49:1903-1914.

-17 Amundsen BH, Helle-Valle T, Edvardsen T, Torp H, Crosby J, Lyseggen E, Stoylen A, Ihlen H, Lima JA, Smiseth OA, Slordahl SA: Noninvasive myocardial strain measurement by speckle tracking echocardiography: validation against sonomicrometry and tagged magnetic resonance imaging. J Am Coll Cardiol 2006;47:789-793.

- 18 Haugaa KH, Edvardsen T, Leren TP, Gran JM, Smiseth OA, Amlie JP: Left ventricular mechanical dispersion by tissue Doppler imaging: a novel approach for identifying highrisk individuals with long QT syndrome. Eur Heart J 2009;30:330-337.

$\checkmark 19$ Haugaa KH, Amlie JP, Berge KE, Leren TP, Smiseth OA, Edvardsen T: Transmural differences in myocardial contraction in longQT syndrome: mechanical consequences of ion channel dysfunction. Circulation 2010; 122:1355-1363.

20 Morad M, Trautwein W: The effect of the duration of the action potential on contraction in the mammalian heart muscle. Pflugers Arch Gesamte Physiol Menschen Tiere 1968; 299:66-82.

-21 De Ferrari GM, Schwartz PJ: Long QT syndrome, a purely electrical disease? Not anymore. Eur Heart J 2009;30:253-255.

-22 Brugada J, Brugada P, Brugada R: The syndrome of right bundle branch block ST segment elevation in V1 to V3 and sudden death - the Brugada syndrome. Europace 1999; 1:156-166.

23 Probst V, Veltmann C, Eckardt L, Meregalli PG, Gaita F, Tan HL, Babuty D, Sacher F, Giustetto C, Schulze-Bahr E, Borggrefe M, Haissaguerre M, Mabo P, Le MH, Wolpert C, Wilde AA: Long-term prognosis of patients diagnosed with Brugada syndrome: Results from the FINGER Brugada Syndrome Registry. Circulation 2010;121:635-643.

-24 Greenberg H, McMaster P, Dwyer EM Jr: Left ventricular dysfunction after acute myocardial infarction: results of a prospective multicenter study. J Am Coll Cardiol 1984;4:867-874.

-25 Buxton AE, Lee KL, Hafley GE, Pires LA, Fisher JD, Gold MR, Josephson ME, Lehmann MH, Prystowsky EN: Limitations of ejection fraction for prediction of sudden death risk in patients with coronary artery disease: lessons from the MUSTT study. J Am Coll Cardiol 2007;50:1150-1157.
-26 Zipes DP, Wellens HJ: Sudden cardiac death. Circulation 1998;98:2334-2351.

27 Verma A, Marrouche NF, Schweikert RA, Saliba W, Wazni O, Cummings J, AbdulKarim A, Bhargava M, Burkhardt JD, Kilicaslan F, Martin DO, Natale A: Relationship between successful ablation sites and the scar border zone defined by substrate mapping for ventricular tachycardia post-myocardial infarction. J Cardiovasc Electrophysiol 2005;16:465-471.

28 Han J, Moe GK: Nonuniform recovery of excitability in ventricular muscle. Circ Res 1964;12:44-60.

29 Vassallo JA, Cassidy DM, Kindwall KE, Marchlinski FE, Josephson ME: Nonuniform recovery of excitability in the left ventricle. Circulation 1988;78:1365-1372.

30 Endresen K, Amlie JP, Forfang K, Simonsen $\mathrm{S}$, Jensen O: Monophasic action potentials in patients with coronary artery disease: reproducibility and electrical restitution and conduction at different stimulation rates. Cardiovasc Res 1987;21:696-702.

-31 Kuchar DL, Thorburn CW, Sammel NL: Late potentials detected after myocardial infarction: natural history and prognostic significance. Circulation 1986;74:1280-1289.

-32 Barr CS, Naas A, Freeman M, Lang CC, Struthers AD: QT dispersion and sudden unexpected death in chronic heart failure. Lancet 1994;343:327-329.

33 Kautzner J, Yi G, Camm AJ, Malik M: Shortand long-term reproducibility of QT, QTc, and QT dispersion measurement in healthy subjects. Pacing Clin Electrophysiol 1994;17: 928-937.

-34 Rosenbaum DS, Jackson LE, Smith JM, Garan H, Ruskin JN, Cohen RJ: Electrical alternans and vulnerability to ventricular arrhythmias. N Engl J Med 1994;330:235-241.

-35 Elgarhi N, Kreuz J, Balta O, Nickenig G, Hoium H, Lewalter T, Schwab JO: Significance of Wedensky Modulation testing in the evaluation of non-invasive risk stratification for ventricular tachyarrhythmia in patients with coronary artery disease and implantable cardioverter-defibrillator. Heart 2008;94:e16.

-36 Makikallio TH, Barthel P, Schneider R, Bauer A, Tapanainen JM, Tulppo MP, Schmidt G, Huikuri HV: Prediction of sudden cardiac death after acute myocardial infarction: role of Holter monitoring in the modern treatment era. Eur Heart J 2005;26:762-769.

37 La Rovere MT, Bigger JT Jr, Marcus FI, Mortara A, Schwartz PJ: Baroreflex sensitivity and heart-rate variability in prediction of total cardiac mortality after myocardial infarction. ATRAMI (Autonomic Tone and Reflexes after Myocardial Infarction) Investigators. Lancet 1998;351:478-484.
38 Yan AT, Shayne AJ, Brown KA, Gupta SN, Chan CW, Luu TM, Di Carli MF, Reynolds HG, Stevenson WG, Kwong RY: Characterization of the peri-infarct zone by contrastenhanced cardiac magnetic resonance imaging is a powerful predictor of post-myocardial infarction mortality. Circulation 2006; 114:32-39.

-39 Schmidt A, Azevedo CF, Cheng A, Gupta SN, Bluemke DA, Foo TK, Gerstenblith G, Weiss RG, Marban E, Tomaselli GF, Lima JA, Wu $\mathrm{KC}$ : Infarct tissue heterogeneity by magnetic resonance imaging identifies enhanced cardiac arrhythmia susceptibility in patients with left ventricular dysfunction. Circulation 2007;115:2006-2014.

40 Gjesdal O, Helle-Valle T, Hopp E, Lunde K, Vartdal T, Aakhus S, Smith HJ, Ihlen H, Edvardsen T: Noninvasive separation of large, medium, and small myocardial infarcts in survivors of reperfused ST-elevation myocardial infarction: a comprehensive tissue Doppler and speckle-tracking echocardiography study. Circ Cardiovasc Imaging 2008; 1:189-196.

-41 Haugaa KH, Smedsrud MK, Steen T, Kongsgaard E, Loennechen JP, Skjaerpe T, Voigt JU, Willems R, Smith G, Smiseth OA, Amlie JP, Edvardsen T: Mechanical dispersion assessed by myocardial strain in patients after myocardial infarction for risk prediction of ventricular arrhythmia. JACC Cardiovasc Imaging 2010;3:247-256.

42 Sen-Chowdhry S, Morgan RD, Chambers JC, McKenna WJ: Arrhythmogenic cardiomyopathy: etiology, diagnosis, and treatment. Annu Rev Med 2010;61:233-253.

43 Saffitz JE: Arrhythmogenic cardiomyopathy and abnormalities of cell-to-cell coupling. Heart Rhythm 2009;6:S62-S65.

44 Amlie JP: Dispersion of repolarization. A basic electrophysiological mechanism behind malignant arrhythmias. Eur Heart J 1997;18: 1200-1202.

45 Turrini P, Corrado D, Basso C, Nava A, Bauce B, Thiene G: Dispersion of ventricular depolarization-repolarization: a noninvasive marker for risk stratification in arrhythmogenic right ventricular cardiomyopathy. Circulation 2001;103:3075-3080.

46 Corrado D, Basso C, Thiene G: Arrhythmogenic right ventricular cardiomyopathy: an update. Heart 2009;95:766-773.

47 Sarvari SI, Haugaa KH, Anfinsen OG, Leren TP, Smiseth OA, Kongsgaard E, Amlie JP, Edvardsen T: Right ventricular mechanical dispersion is related to malignant arrhythmias: a study of patients with arrhythmogenic right ventricular cardiomyopathy and subclinical right ventricular dysfunction. Eur Heart J 2011 [Epub ahead of print]. 